University of Nebraska - Lincoln

DigitalCommons@University of Nebraska - Lincoln

1995

\title{
Fault healing inferred from time dependent variations in source properties of repeating earthquakes
}

Chris Marone

Massachusetts Institute of Technology

John E. Vidale

U.S. Geological Survey

William L. Ellsworth

U.S. Geological Survey

Follow this and additional works at: https://digitalcommons.unl.edu/usgsstaffpub

Part of the Earth Sciences Commons

Marone, Chris; Vidale, John E.; and Ellsworth, William L., "Fault healing inferred from time dependent variations in source properties of repeating earthquakes" (1995). USGS Staff -- Published Research. 372. https://digitalcommons.unl.edu/usgsstaffpub/372

This Article is brought to you for free and open access by the US Geological Survey at DigitalCommons@University of Nebraska - Lincoln. It has been accepted for inclusion in USGS Staff -- Published Research by an authorized administrator of DigitalCommons@University of Nebraska - Lincoln. 


\title{
Fault healing inferred from time dependent variations in source properties of repeating earthquakes
}

\author{
Chris Marone \\ Department of Earth, Atmospheric, and Planetary Sciences, Massachusetts Institute of Technology, Cambridge
}

\author{
John E. Vidale and William L. Ellsworth \\ U. S. Geological Survey, Menlo Park, California
}

\begin{abstract}
We analyze two sets of repeating earthquakes on the Calaveras fault to estimate in-situ rates of fault strengthening (healing). Earthquake recurrence intervals $t_{\mathrm{r}}$ range from 3 to 803 days. Variations in relative moment and duration are combined to study changes in stress drop, rupture dimension, rupture veloo ity, and particle velocity as a function of $t_{r}$. Healing rates and source variations are compared with predictions of laboratoryderived friction laws. Two interpretations of event duration $\tau$ are used: one in which $\tau$ is given by the ratio of slip to particle velocity and one in which it scales as rupture dimension divided by rupture velocity. Our data indicate that faults strengthen during the interseismic period. We infer that source dimension decreases with $t_{r}$ due to aseismic creep within the region surrounding the repeating events. Stress drop increases 1-3MPa per decade increase in $t_{n}$ which represents an increase of a factor of 2-3 relative to events with $t$, between 10 and 100 days. This rate of fault healing is consistent with extrapolations of laboratory measurements of healing rates if fault strength is high, on order of $60 \mathrm{MPa}$, and stress drop is roughly $10 \%$ of this value.
\end{abstract}

\section{Introduction}

Laboratory experiments show that friction of simulated faults increases with time of stationary contact and with decreasing slip rate [Dieterich, 1972; Beeler et al., 1994]. These data indicate that faults will strengthen (heal) during the interseismic period. In laboratory experiments, friction increases by 0.03 to 0.08 (5$10 \%$ of the absolute value) per decade increase in hold time [Scholz, 1990; Beeler et al., 1994; Kamer et al., 1995]. However, field-based estimates of fault bealing imply that stress drop increases by a factor of 2-5 per decade increase in earthquake ro currence interval [Kanamori and Allen, 1986; Scholz et al., 1986]. This discrepancy could be due to higher healing rates on natural faults or differences between the way healing rate is measured: laboratory experiments measure changes in "static" frictional strength, whereas seismic estimates derive from stress drop, which is proportional to the difference between static and dynamic friction. Also, existing field estimates have been made by comparing faults from different tectonic regions and with different total offsets and recent slip rates. Thus, these estimates could be contaminated by other effects.

Earthquakes that repeatedly rupture the same fault patch offer the opportunity to improve our understanding of bealing rates of

Copyright 1995 by the American Geophysical Union.

Paper number 95GL03076

0094-8534/95/95GL-03076\$03.00 natural faults and to assess the efficacy of laboratory-derived friction laws in nature. In this paper we use repeating earthquakes to examine the effect of recurrence interval on source properties and to estimate in-situ the rate of fault healing. We compare source variations and the seismic healing rate with prodictions of laboratory-derived friction laws.

\section{Repeating Earthquakes}

Recent developments in the recognition and analysis of repeating earthquakes allow for high resolution estimates of subtle differences between events [Poupinet et al., 1984; Vidale et al., 1994; Ellsworth, 1995; Nadeau et al., 1995; Beroza et al., 1995]. We use two sets of $M \approx 1.5$ earthquakes recorded by the Northern California Seismic Network (NCSN) during the period 19801994 [Ellsworth, 1995]. Seismic properties of the events, analysis techniques, and implications for earthquake forecasting have been described in detail [Vidale et al., 1994; Ellsworth, 1995]. Here, we summarize only a few pertinent aspects of the events.

The sequences occur on the Calaveras fault just beyond the southern limit of the 1984 M6.2 Morgan Hill rupture (Figure 1). The NCSN catalog is complete to about $M=1.0$ for this locale, making it possible to accurately identify all events belonging to CA1 or CA2 since 1980; hence, the seismic recurrence interval is known. The sequences occur at depths of 6 and 8km, respectively, and are separated by $\mathbf{2 k m}$ along strike (Figure 1). The northernmost sequence, CA1, consists of 19 events of $M$ 1.4-1.6. The second sequence, CA2, consists of 14 events of similar magnitude. Waveforms for events within each set are nearly identical from the P-wave through the coda [Ellsworth, 1995] and cross correlation techniques show that relative centroid locations are within $\pm 10 \mathrm{~m}$ [Vidale et al., 1994]. Because the relative location uncertainties are smaller than the likely rupture dimension (diameter $50-100 \mathrm{~m}$ ) each set is considered to represent repeated rupture of the same fault patch.

\section{Observations of Moment and Duration}

Of the 19 events in the CA1 sequence, one occurred before the 1984 Morgan Hill earthquake. Since we do not know whether the CA1 patch slipped during the Morgan Hill mainshock, we also exclude the first aftershock, leaving 17 events with known recurrence interval (Figure 2). For these events, moment increased 10 $15 \%$ per decade change in $t_{r}$ (Figure 2a). Source duration decreased systematically with $t_{r}$ at a rate of about $35 \%$ per decade for both $\omega^{-2}$ and $\omega^{-3}$ source models (Figure $2 b$ ).

The CA2 sequence (Figure 3) contains fewer aftershocks and longer average repeat times than CA1. With the exception of one event, an aftershock that occurred 11 days after the Morgan Hill 


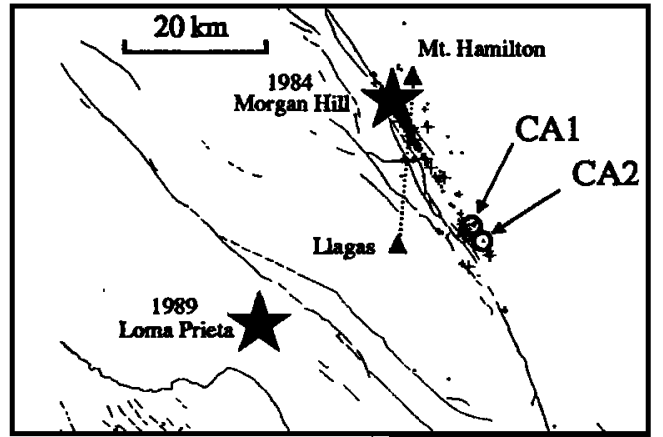

Flgure 1. Location of the CA1 and CA2 repeating sequences on the Calaveras fault, California. Seismicity along the Calaveras fault is shown by crosses. Stars denote epicenters of largest recent earthquakes. Prescott et al. [1986] made geodetic measurements between Llagas and Mt. Hamilton. (After Ellsworth, 1995.)

event, the CA2 sequence shows decreasing moment with recurrence interval (Figure 3a).

\section{Analysis of Source Parameter Variations}

We consider possible variations in source parameters in the context of a circular earthquake rupture of radius $r$. In this case,
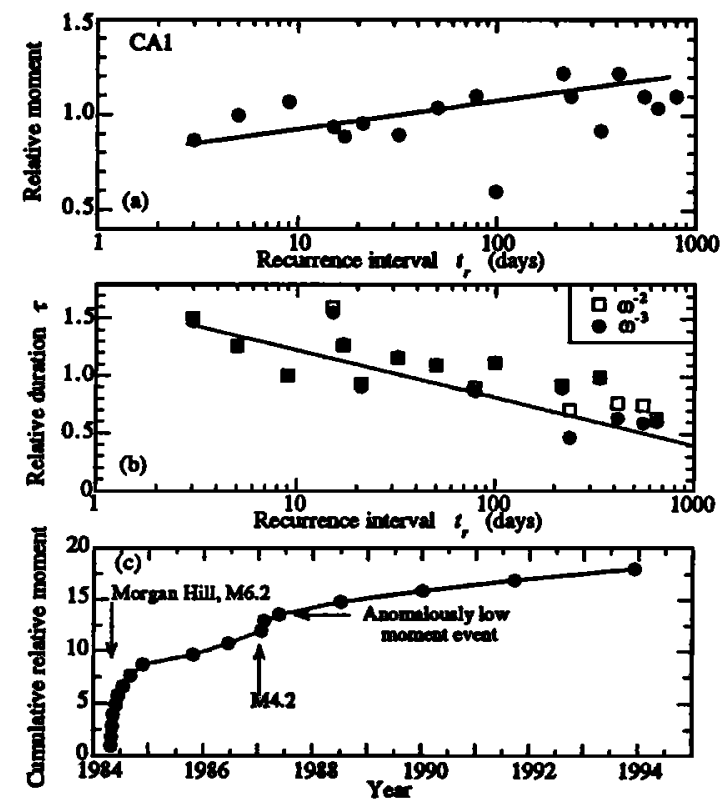

Figure 2. Data for the CA1 sequence of 18 events on the $\mathrm{Ca}$ laveras fault. Relative moment was determined by comparing spectral levels at $5 \mathrm{~Hz}$ and corner frequency $f_{c}$ was estimated by normalizing the spectra at $5 \mathrm{~Hz}$ and comparing the observed spectral slope with normalized theoretical spectra within the available frequency range $(<20 \mathrm{~Hz})$ [Vidale et ah, 1994]. (a) Line shows $15 \%$ increase in moment per decade increase in recurrence interval. (b) Duration is proportional to $f_{c}^{-1} \cdot \tau=1.0$ corresponds to event duration of $0.033 \mathrm{~s}$. Line shows $35 \%$ decrease in relative duration per decade increase in $t_{r}$. Duration decreases systematically with $t$, and is insensitive to differences between source models. We do not have duration data for the December 1993 event. (c) Cumulative moment release vs. event date. The combination of aftershocks of 1984 Morgan Hill earthquake and background seismicity results in the unusually large range of recurrence intervals [Ellsworth, 1995]. A nearby M4.2 event in early 1987 triggered three events, one with anomalously low moment.
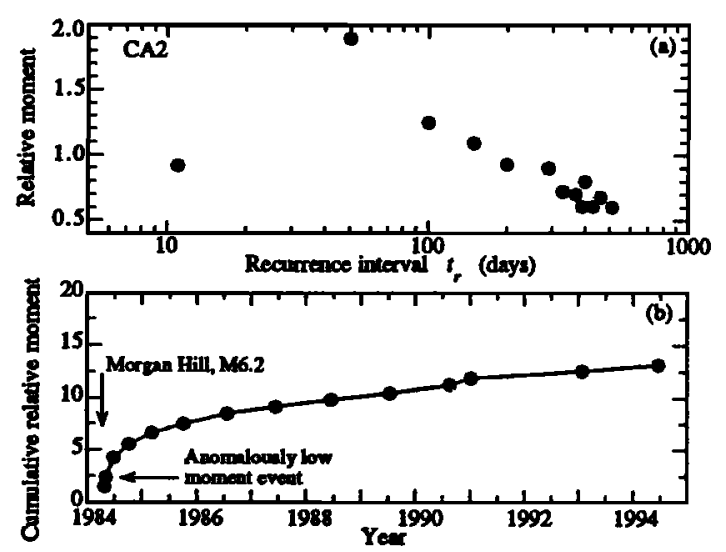

Figure 3. Data for the CA2 sequence of 14 repeating earthquakes. (a) Relative moment vs. recurrence interval. We were unable to determine $f_{c}$ for the $\mathrm{CA} 2$ sequence, which appears to have shorter duration than CA1. Moment decreased systematically with recurrence interval for interevent times greater than $\mathbf{5 0}$ days. (b) cumulative moment release vs. event date showing decay of the aftershock rate to a roughly constant moment release rate.

moment is $M_{c}=\pi r^{2} G u$, where $G$ is shear modulus and $u$ is average slip, and average stress drop is $\Delta \sigma=7 \pi G u / 16 r$, which yields $M_{0}=16 \Delta \sigma r^{3} / 7$, leading to:

$$
\frac{d M_{o}}{d t_{r}}=\frac{16}{7}\left[r^{3} \frac{d \Delta \sigma}{d t_{r}}+3 \Delta \sigma r^{2} \frac{d r}{d t_{r}}\right]
$$

where $d(\Delta \sigma) / d$, and $d r / d t$, are the seismic bealing rate and dependence of rupture dimension on interevent time, respectively. Added constraint is provided by estimates of characteristic event duration $\tau$ (Figure 2b). Two interpretations of $\tau$ may be made.

First, we take $\tau$ as the time required for rupture to expand over the entire fault area: $\tau=r V_{r}$, where $V_{r}$ is average rupture velocity. In this case, variations in $\tau$ with interevent time are due to variations in source dimension or average rupture velocity

$$
\frac{d \tau}{d t_{r}}=V_{r}^{-1} \frac{d r}{d t_{r}}-\frac{r}{V_{r}^{2}} \frac{d V_{r}}{d t_{r}}
$$

By combining (1) and (2) we can show the range of possible solutions for the repeating earthquake data in terms of changes in stress drop, rupture radius, and rupture velocity. Figure 4a shows the locus of possible solutions for a given value of $d M / d t_{\text {, }}$ taking $\Delta v \Delta t_{r}=-35 \% / d e c a d e$ (from Figure $2 b$ ). Although the data do not allow a unique solution, two common assumptions may be considered: constant rupture dimension and constant rupture velocity.

Because of our interpretation of $\tau$, leading to equation (2), if the source radius is independent of $t_{r}$ (upper horizontal, dashed line in Figure $4 a$ ), rupture velocity must increase by $35 \%$ per dec ade increase in $t_{r}$, which would imply a $15 \% /$ decade increase in stress drop (Figure 4a). Alternatively, if rupture velocity is constant, $r$ decreases $13 \mathrm{~m} /$ decade and stress drop increases $120 \%$ per decade change in $t_{r}$. The CA2 sequence shows roughly a $75 \%$ decrease in moment per decade. We do not have duration data for CA2. Assuming the same change in duration as for CA1, the CA2 events indicate a 35\%/decade increase in stress drop and a $13 \mathrm{~m} /$ decade decrease in rupture radius.

Equation (2) and Figure $4 \mathrm{a}$ are based on $\tau$ being the time ro quired for rupture to expand over the entire fault area. An alternative view is that $\tau$ is the ratio of slip to particle velocity $V_{p}$ on the fault: $\tau=u / V$. In this case, $\tau$ would correspond to the local 

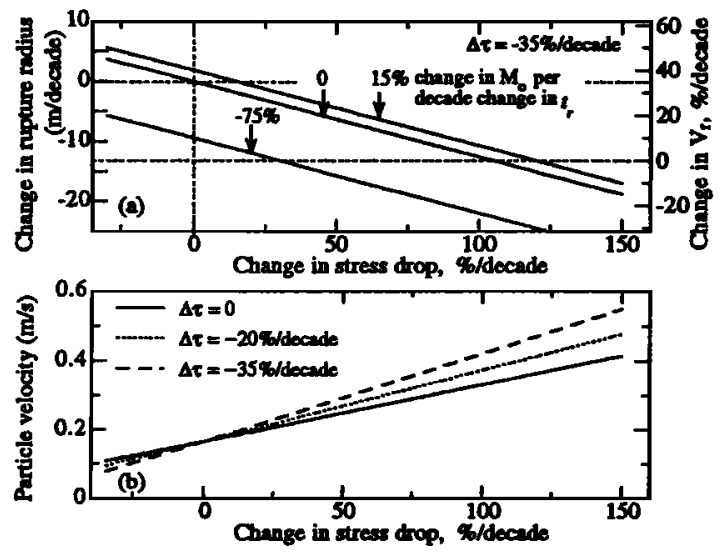

Figure 4. Changes in earthquake source parameters for two models relating changes in moment and duration. In (a) event duration is $\tau=r / V_{r}$, and in (b) $\tau=u / V_{p}$. Changes are per decade change in recurrence interval and are relative to an event with $t_{r}=100$ days, for which $M_{e}=5.5 \times 10^{11} \mathrm{Nm}, \tau=0.025 \mathrm{~s}, r=37.5 \mathrm{~m}, \Delta \sigma=4.6 \mathrm{MPa}$ and average slip and rupture velocity are $0.4 \mathrm{~cm}$ and $1.5 \mathrm{~km} / \mathrm{s}$, respectively. (a) Locus of possible solutions for observed moment and duration variations. The plot is made for $\Delta \tau / \Delta t,=-35 \% /$ decade. CA1 sequence shows $\Delta M_{0} / \Delta t_{r}=15 \%$, thus for constant rupture velocity (lower, horizontal dashed line) stress drop increases $120 \% /$ decade and source radius decreases $13 \mathrm{~m} /$ decade. The CA2 sequence indicates $\approx 75 \% M_{0}$ reduction per decade and the line is drawn assuming the same change in duration and average event size as CA1. (b) Relationship between absolute particle velocity and change in stress drop for constant rupture size and $\tau=u / V$. The change in stress drop is directly proportional to the change in $M_{o}$, thus for $35 \% /$ decade decrease in $\tau$ and $15 \% /$ decade increase in stress drop, $V_{p}$ increases $0.03 \mathrm{~m} / \mathrm{s}$ per decade increase in $t_{r}$.

rise time on the fault, which is comparable to average rupture duration for some fault models. Combining this with the relation between $M_{0}$ and average slip, yields: $V_{p}=M_{0} / \tau G \pi r^{2}$. Differentiating this with respect to interevent time and combining it with (1) gives a relation between $d V / d t$, and $d(\Delta \sigma) V d t$, as a function of $d \tau / d_{r}$ which is plotted vs. $V_{p}$ in Figure $4 b$. As expected, particle velocity scales directly with stress drop. For a given increase in stress drop, particle velocity increases as the change in duration decreases (Figure 4b). The line of constant duration has slope of $0.04\left(\mathrm{~m} \mathrm{~s}^{-1}\right) / \mathrm{MPa}$, which, consistent with our rupture velocity, is about a factor of two lower than experimental measurements and the theoretical relation for a self-similar rupture with uniform stress drop: $V, \approx \Delta \sigma V_{r} / G$ [Scholz 1990, p. 173].

For the CA1 sequence, we can estimate absolute changes in stress drop and particle velocity (Figure 5). For constant $V_{r}$, stress drop increases 2-3MPa per decade increase in $t_{r}$ (Figure $5 a)$. On the other hand, $V_{r}$ may increase with $t_{r}$ if rupture resistance $S$ decreases with $t_{n}$ which is expected if average $\sigma_{b}$ on the fault plane increases with $t_{r}\left(S=\left(\sigma_{y}-\sigma_{0}\right) /\left(\sigma_{o}-\sigma_{d}\right)\right.$, where $\sigma_{o}, \sigma_{r} \sigma_{d}$ are the local values of initial stress, yield strength, and dynamic frictional strength, respectively). However, even a 20\%/decade increase in $V_{r}$ does not change significantly the estimate of fault healing rate, which is in the range 1-3MPa/decade (Figure 5a).

To get a further sense of the uncertainty in this estimate, we use the second interpretation of $\tau$ to evaluate changes in the average particle velocity of the CA1 events (Figure 5b). The data show about a $0.05 \mathrm{~m} / \mathrm{s}$ increase in $V_{p} /$ decade, which using the above relation between asymptotic $V_{p}$ and dynamic stress drop indicates $1 \mathrm{MPa}$ /decade increase in stress drop. Thus the two approaches yield similar estimates of seismic bealing rate.

\section{Discussion}

Frictional strengthening in laboratory experiments is generally attributed to increased contact area or enhanced adhesion at asperity contacts [Scholz, 1990]. Applied to natural faults, the lab data predict: 1) that fault strength will increase with increasing seismic recurrence interval and 2) that the size of individual ruptures will be constant or increase slightly with $t_{r}$ presuming that ruptures correspond to individual frictional contacts.

Strictly, point 1 relates only to yield strength $\sigma_{y}$ and not necessarily to seismically-estimated healing rate since laboratory measurements are made of the increase in peak friction with waiting time, whereas seismic healing rate is based on changes in stress drop $\Delta \sigma=\sigma_{y}-\sigma_{d}$. The values may be compared if healing causes increased yield strength $\sigma$, but no change in dynamic fric tional strength $\sigma_{d}$. Then for failure under uniform initial stress $\sigma_{\text {. }}$ $\left(\sigma_{\sigma} \approx \sigma_{y}\right)$ the lab data predict that stress drop increases by the amount of frictional healing: 0.03 times effective normal stress. Taking $18 \mathrm{MPa} / \mathrm{km}$ as an average effective lithostatic gradient, our repeating earthquake sequences have effective normal stress $\sigma_{n}=100 \mathrm{MPa}$, and thus the laboratory healing rates predict that stress drop will increase about $3 \mathrm{MPa}$ per decade increase in $t_{r}$

Since frictional healing rate scales with strength [Scholz and Engelder, 1976], faults that are significantly weaker or that slide under significantly lower normal stress should exhibit lower healing rates; for $\sigma_{n}=10 \mathrm{MPa}$, the predicted healing rate would be $\leq 0.3 \mathrm{MPa}$ decade.

The laboratory prediction agrees with our in-situ estimate of seismic healing if rupture velocity is approximately independent of recurrence interval (Figure 5a). However, that requires a sy stematic decrease in rupture size with recurrence interval, which is counter to point 2 above. For the CA1 sequence, this difficulty can be avoided if one takes the view that duration is local slip duration at a point on the fault. In this case, the healing rate is about $1 \mathrm{MPa}$ decade (Figure $5 \mathrm{~b}$ ) and no change in rupture size is required. However, the CA2 data cannot be explained in this way. Decreasing moment with recurrence interval requires either that
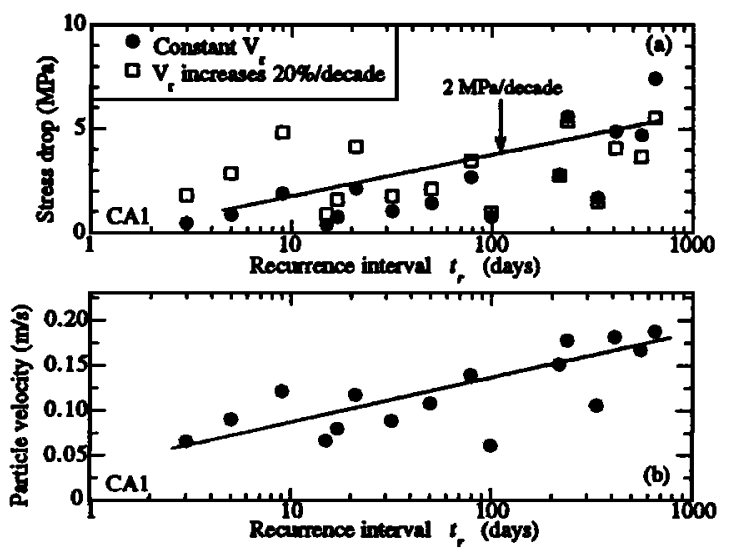

Figure 5. Stress drop (a) and particle velocity (b) for the CA1 so quence. Each plot uses data of Figure $2 a$ and the $\omega^{-2}$ data of Figure $2 \mathrm{~b}$ scaled to absolute values. (a) Stress drop assuming duration $\tau=r / V_{r}$. The data show a $2-3 \mathrm{MPa} /$ decade change in stress drop. Our techniques resolve relative changes much better than absolute values and thus the possible indication that stress drop goes to zero at finite $t$, is not significant. (b) Particle velocity for the CA1 events assuming constant rupture size and that duration is $\tau=u / V_{p}$. Line shows $0.05 \mathrm{~m} / \mathrm{s}$ increase in $V_{p}$ per decade, which corresponds to a $1 \mathrm{MPa} /$ decade increase in stress drop. Slip increases from about 0.3 to $0.5 \mathrm{~cm}$ over the range or $t_{r}$ 
stress drop or source radius decrease with recurrence interval. Although either of these are possible under special conditions, a negative change in stress drop is less likely because it implies do creasing peak friction with hold time, which is equivalent to velocity-strengthening frictional behavior. In this case, the fault patch would not be expected to fail seismically.

On the other hand, geodetic measurements on the line shown in Figure 1 [Prescott et al., 1986] show steady slip at a rate that mimics the recurrence rate of the repeating events [Ellsworth, 1995]. This, coupled with the lack of seismicity in regions surrounding the repeating events suggests that these regions slip aseismically. Thus, the CA1 and CA2 fault patches may repro sent frictional contacts that are continually loaded by aseismic creep in the surrounding regions. In this case, longer intervals between events would be expected to result in greater aseismic slip around the rupture patches and thus greater slip at the edges of the patch prior to nucleation. In the context of rate/state friction laws, the edges of the patch would represent regions of slight velocity weakening to velocity neutral frictional behavior, producing conditionally unstable behavior.

Although we focus on time-dependent frictional strengthening as a mechanism to explain the observed source variations, we cannot rule out other effects such as fluid pressure variations or other changes in the state of stress [e.g., Sleep and Blanpied, 1994; Palmer et al., 1995]. For example, compaction and fluid pressure variations following the 1984 Morgan Hill earthquake could modify stress drop and source duration. However, it is difficult to envision how this would lead to systematic source variations with recurrence interval. Moreover, the frictional healing mechanisms we discuss are expected to operate even if other processes are active.

\section{Conclusions}

Data from the CA1 sequence show that stress drop increases $1-3 \mathrm{MPa}$ /decade increase in $t_{r}$ These data show that characteristic event duration decreases with waiting time, which is consistent with increasing particle velocity and/or increasing rupture velocity and decreasing source radius with $t_{\boldsymbol{r}}$. Although interpretation of CA2 is less certain, these data favor the interpretation that source radius decreases slightly with increasing $t_{r}$ presumably due to aseismic creep on the perimeter of the rupture patch.

Our laboratory-based interpretation of healing rate differs from previous estimates [e.g., Scholz et al., 1986], which focus on the rate of change of the absolute friction value and the expected fractional change in stress drop with recurrence interval assuming total stress drop. For a stress drop of a few $\mathrm{MPa}$, our laboratorybased predictions and seismic estimates indicate that faults heal at rates sufficient to produce a factor of 2-6 increase in stress drop per decade increase in recurrence interval. These healing rates are consistent with previous work based on differences in scaling properties of intraplate and interplate earthquakes. However, the seismic healing rates are consistent with laboratory measurements only if fault strength is bigh, on order of $60 \mathrm{MPa}$. If faults are significantly weaker, with effective normal stresses and shear strengths of order $10 \mathrm{MPa}$, predicted healing rates are a factor of 5-10 lower than our seismic estimates. Further laboratory work is necessary to determine healing rates at elevated temperature and fluid pressure for comparison with in-situ, seismic estimates.
Acknowledgments. We thank N. Deichmann, E. Humphreys, M. Blanpied, J. Boatwright, C. Scholz and two anonymous reviewers for critical comments, suggestions, and discussion. CM was supported by USGS award 1434-94-G-2417, NSF grant EAR-9316082, and a KertMoGee career development chair at MIT.

\section{References}

Beeler, N. M., T. E. Tullis, and J. D. Weeks, The roles of time and displacement in the evolution effect in rock friction, Geophys. Res. Lett., 2I, 1987-1990, 1994.

Beroza, G. C., A. T. Cole, and W. L. Ellsworth, Stability of coda wave attenuation during the Loma Prieta, California, earthquake sequence, J. Geophys. Res., 100, 3977-3987, 1995.

Dieterich, J. H., Time-dependent friction in rocks, J. Geophys. Res., 77, 3690-3697, 1972.

Ellsworth, W. L., Characteristic earthquakes and long-term earthquake forecasts: implications of Central California Seismicity, in Urban Disaster Mitigation: the Role of Science and Technology, Eds. Cheng, F.Y., and Sheu, M.S., Pp. 1-14, Elsevier, 1995.

Kanamori, H. C. R. Allen, Earthquake repeat time and average stress drop, in Earthquake Source Mechanics. AGU Geophys. mono. 37, ods. S. Das et al., pp. 227-236, 1986.

Karner, S. L., C. Marone, and B. Evans, Experimental analysis of lithification and healing in fault gouge, Eos Trans. AGU, 76, 281,1995.

Nadeau, R. M., W. Foxall, and T. V. McEvilly, Clustering and periodic recurrence of microearthquakes on the San Andreas fault at Parkfield, California, Science, 267, 503-508, 1995.

Palmer, R., R. Weldon, E. Humphreys, and F. Saucier, Earthquake recurrence on the southern San Andreas modulated by fault-normal stress, Geophys. Res. Lett., 22, 535-538, 1995.

Prescott, W. H., N. E. King, and G. Guohua, Preseismic, coseismic, and postseismic deformation associated with the 1984 Morgan Hill, California, earthquake, in The 1984 Morgan Hill, CA earthquake, eds. J. H. Bennett and R. W. Sherburne, pp. 137-148, Cal. Div. Mines and Geo. Spec. Pub. 68, 1986.

Poupinet, G., W. L. Ellsworth, and J. Fréchet, Monitoring velocity variations in the crust using earthquake doublets: An application to the Calaveras fault, California, J. Geophys. Res., 89, 5719-5731, 1984.

Scholz, C. H., The Mechanics of Earthquakes and Faulting, Cambridge University Press, Cambridge, UK, 1990.

Scholz, C. H. and J. T. Engelder, The role of asperity indentation and ploughing in rock friction; I. Asperity creep and stick slip, Int. J. Rock Mech. Min Sci, 13, 149-154, 1976.

Scholz, C. H., C. A. Aviles, and S. G. Wesnousky, Scaling differences between large interplate and intraplate earthquakes, Bull. Seis. Soc. Am, 76, 65-70, 1986.

Sleep, N. H., and M. L. Blanpied, Ductile creep and compaction: a mechanism for transiently increasing fluid pressure in mostly sealed fault zones, Pure Appl. Geophys., 143, 9-40, 1994.

Vidale, J. E., W. L. Ellsworth, A. Cole, and C. Marone, Rupture variation with recurrence interval in eighteen cycles of a small earthquake, $\mathrm{Na}$ ture, 368, 624-626, 1994.

W. L. Ellsworth and J. E. Vidale, U. S. Geological Survey, MS-977, 345 Middlefield Road, Menlo Park, CA 94025 (email: ellswrth@andreas.wr.usgs.gov, vidale@ vidale.wr.usgs.gov

C. Marone, Dept. of Earth, Atmospheric, and Planetary Sciences, MIT, Cambridge, MA 02139 (email: cjm@westerly.mit.edu)

(Received May 8, 1995; Revised July 3, 1995; Accepted August 29, 1995.) 